ARTICLE

https://doi.org/10.1038/s41467-019-13829-4

\title{
Electrooxidation enables highly regioselective dearomative annulation of indole and benzofuran derivatives
}

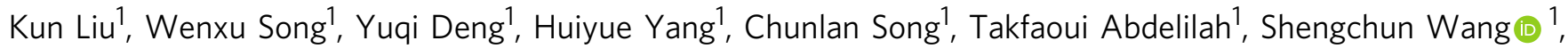
Hengjiang Cong (D) ${ }^{1}$, Shan Tang $^{1} \&$ Aiwen Lei ${ }^{1 \star}$

The dearomatization of arenes represents a powerful synthetic methodology to provide three-dimensional chemicals of high added value. Here we report a general and practical protocol for regioselective dearomative annulation of indole and benzofuran derivatives in an electrochemical way. Under undivided electrolytic conditions, a series of highly functionalized five to eight-membered heterocycle-2,3-fused indolines and dihydrobenzofurans, which are typically unattainable under thermal conditions, can be successfully accessed in high yield with excellent regio- and stereo-selectivity. This transformation can also tolerate a wide range of functional groups and achieve good efficiency in large-scale synthesis under oxidant-free conditions. In addition, cyclic voltammetry, electron paramagnetic resonance (EPR) and kinetic studies indicate that the dehydrogenative dearomatization annulations arise from the anodic oxidation of indole into indole radical cation, and this process is the ratedetermining step. 
B reaking the aromatic systems of electron-rich arenes or heteroarenes provides three-dimensional chemicals of high added value ${ }^{1-7}$. In this field, polycyclic indoline-based alkaloids derived from indole dearomatization have promoted chemists to develop numerous methods for their efficient preparation owing to the important biological activities ${ }^{8-11}$. Over the past several decades, dearomative annulation of indoles has served as one of the most popular avenues for preparing polycyclic indoline skelotons ${ }^{12-15}$. Some powerful protocols like cyclopropanation $^{16,17}$, 1,3-dipolar cycloadditions ${ }^{18}, \quad[2+2]$ photo-cycloadditions $^{19}$, Diels-Alder ${ }^{20-22}$, and cascade electrophilic addition/annulation reactions ${ }^{23-26}$ have been well established. In these cases, most of the strategies took advantage of the $\mathrm{C} 2-\mathrm{C} 3 \pi$ bond or the inherent strong nucleophilicity of $\mathrm{C} 3$ position, and had the advantage of rapid construction for highly functionalized indoline frameworks in one step. On the other hand, recent advances in oxidation-induced $\mathrm{C}-\mathrm{H}$ functionalization have opened up other possibilities for constructing various polycyclic indolines ${ }^{27-31}$. In this regard, many efficient strategies for activating indoles have been developed under mild conditions $^{32-36}$. In 2012, Ma and coworkers ${ }^{37}$ reported an attractive procedure to prepare polycyclic pyrroloindolines with iodine as oxidizing agents. In 2014, the group of Xiao developed a visible light-induced intramolecular oxyamidation reaction of indoles using molecular oxygen as the oxidant ${ }^{38}$. Obviously, significant progress has been made in the synthesis of five-membered ringfused 2,3-indolines. As compared with this, these types of methodologies failed to provide a practically efficient route toward biologically valuable six to bigger-membered heterocycle- fused indolines (Fig. 1a) ${ }^{39-44}$. Therefore, it is highly appealing to develop efficient approaches to allow for their preparation.

Electrochemical oxidation offers a mild and efficient alternative to the use of hazardous chemical oxidants and demonstrates unique reaction selectivity compared with the results under thermal conditions ${ }^{45-59}$. With sufficient potential bias, organic substrates can lose one electron at the anode to generate highly reactive intermediates ${ }^{60-63}$. In 2017, our group developed an electrochemical dearomative $[3+2]$ annulation between phenols and $N$-acetyl indoles for the synthesis of benzofuro[3,2-b]indolines (Fig. 1b) ${ }^{64}$. This dearomative annulation was proved to be proceeded through the radical/radical cross-coupling between in situ generated indole radical cations and phenol radicals, but only five-membered ring-fused 2,3-indolines were afforded. The approach toward dehydrogenative $[4+2]$ dearomatization annulation of indoles has been rare. Fascinated by the distinctive reactivity of indole radical cation, we anticipate that the reports for adequately studied alkene radical cation may give a hand to the development of dehydrogenative $[4+2]$ annulation of indoles ${ }^{65,66}$. For example, in 2018 , our group has demonstrated a dehydrogenative $[4+2]$ annulation of styrenes with alkynes to afford a variety of six-membered aromatic rings ${ }^{67}$. This reaction went through the nucleophilic attack of dienophile to alkene radical cation and second nucleophilic attack from arene to in situ generated alkenyl carbon cation to afford the cyclic intermediates. Therefore, we envision that introducing a reagent that incorporates seperate radical and nucleophilic centers or two nucleophilic centers to react with indoles radical cation may achieve the desired $[4+2]$ dearomative annulation. Very recently, Vincent

a Important molecules containing six to bigger-membered heterocycle-fused indolines
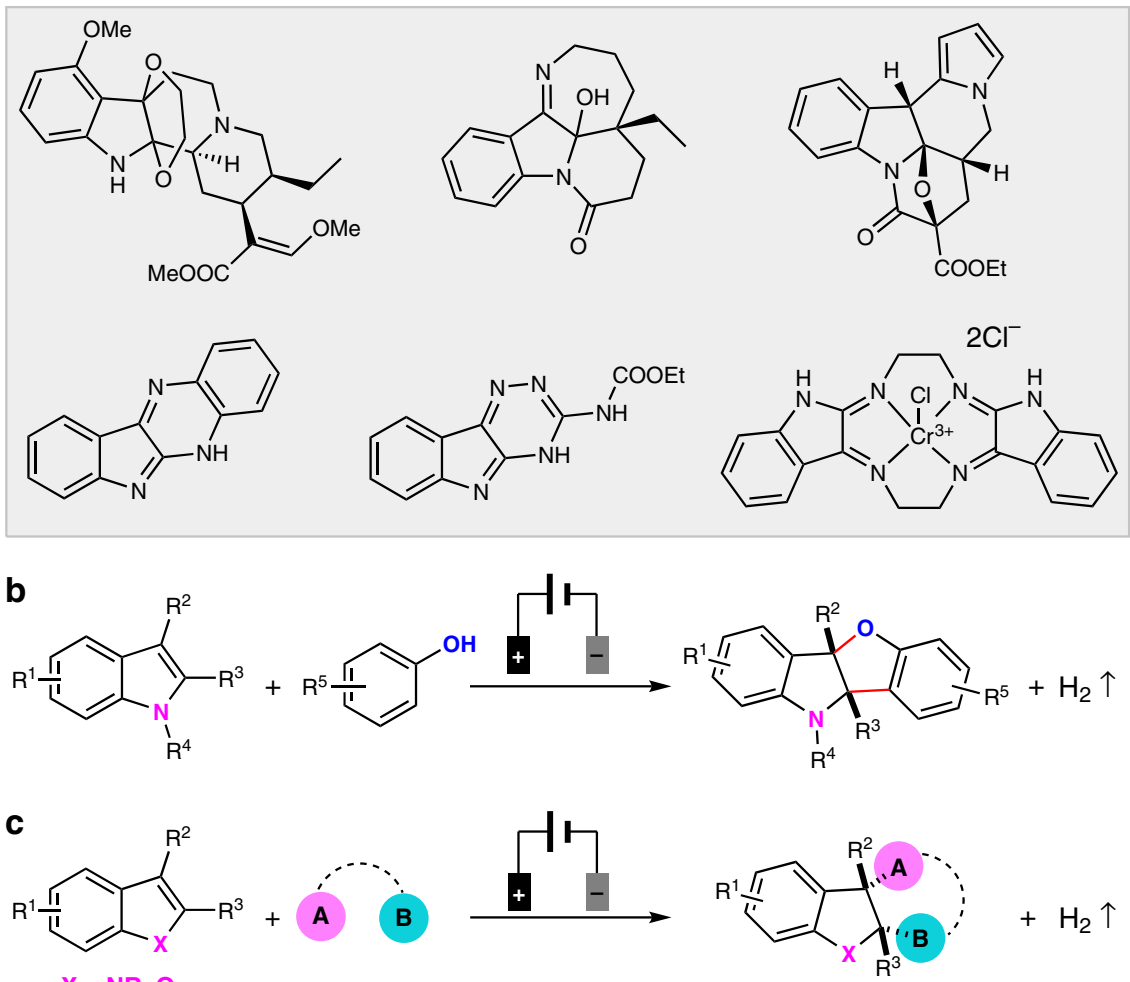

$[3+2],[4+2],[5+2]$ and $[6+2]$ annulation Five to eight-membered rings

High regio- and diasteroselectivity

Fig. 1 Electrooxidation enables dearomative annulation of indoles to synthesize polycyclic indoline derivatives. a Important molecules containing six to bigger-membered heterocycle-fused indolines. b Electrochemical [3+2] annulation between indole and phenol to access benzofuro[3,2-b]indolines. c Electrochemical $[3+2]$, $[4+2]$, [5+2], and [6+2] dearomative annulation of indoles and benzofurans with various bis-nucleophiles. 


\section{Table 1 Investigation of reaction conditions ${ }^{a}$.}

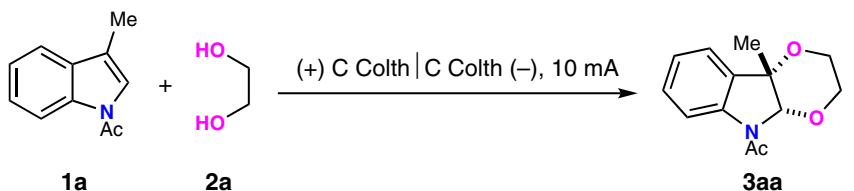

\begin{tabular}{lll}
\hline Entry & Variation from standard conditions & Yield \\
\hline 1 & None & $75 \%$ \\
2 & $5 \mathrm{~mA}, 8 \mathrm{~h}$ & $74 \%$ \\
3 & $20 \mathrm{~mA}^{2} \mathrm{~h}$ & $73 \%$ \\
4 & ${ }^{n} \mathrm{Bu}_{4} \mathrm{NPF}_{6}$ instead of ${ }^{n} \mathrm{Bu}_{4} \mathrm{NBF}_{4}$ & $65 \%$ \\
5 & ${ }^{n} \mathrm{Bu}_{4} \mathrm{NClO}_{4}$ instead of ${ }^{n} \mathrm{Bu}_{4} \mathrm{NBF}_{4}$ & $43 \%$ \\
6 & $0.75 \mathrm{~mL}$ of $\mathbf{2 a}$ & $61 \%$ \\
7 & $2.0 \mathrm{~mL}$ of $\mathbf{2 a}$ & $77 \%$ \\
8 & Carbon rod anode & $7 \%$ \\
9 & Carbon plate anode & $12 \%$ \\
10 & Pt plate cathode & $55 \%$ \\
11 & DCM instead of MeCN \\
12 & Without electric current, under air \\
13 & Conducted under air & n.d. \\
\hline
\end{tabular}

aReaction conditions: carbon cloth anode $(20 \mathrm{~mm} \times 20 \mathrm{~mm})$, carbon cloth cathode $(20 \mathrm{~mm} \times 20 \mathrm{~mm})$, constant current $=10 \mathrm{~mA}\left(J_{\text {anode }}=2.5 \mathrm{~mA} \mathrm{~cm}^{-2}\right), \mathbf{1 a}(0.50 \mathrm{mmol}), \mathbf{2 a}(1.2 \mathrm{~mL}),{ }^{n} \mathrm{Bu} 4 \mathrm{NBF} 4(0.30$ $\mathrm{mmol}), \mathrm{MeCN}(9.0 \mathrm{~mL}), \mathrm{N}_{2}$, r.t., $4 \mathrm{~h}(3 . \mathrm{OF})$. Isolated yields were shown. n.d. not detected, n.r. no reaction.

and coworkers reported an electrochemical dearomative dialkoxylation and diazidation of indoles with methanol or $\mathrm{TMSN}_{3}$, albeit only one example of intermolecular dearomatization annulation was reported in $43 \%$ yield with ethylene glycol ${ }^{68}$. Here we present a versatile protocol for efficient electrooxidative [ $4+$ 2] dearomatization annulation between indoles and various bisnucleophiles that contain $\mathrm{O}-, \mathrm{N}$-, and $\mathrm{S}$-nucleophilic groups. This method can be extended to intermolecular $[3+2],[5+2]$, and $[6+2]$ annulations. Many biologically valuable five to eightmembered heterocycle-fused 2,3-indolines are constructed under external oxidant- and catalyst-free conditions, which are unattainable with thermal methods. Benzofurans can also serve as two-carbon synthon to afford dihydrobenzofuran. Notably, excellent regio- and stereo-selectivity are achieved in these transformations (Fig. 1c).

\section{Result}

Investigation of reaction conditions and substrate scope. To probe the feasibility of this strategy, we commenced the study on the reaction of 3-methyl $\mathrm{N}$-acetyl indole (1a) with ethylene glycol (2a). To our delight, the desired dearomative $[4+2]$ annulation product 3aa was obtained in $75 \%$ yield under $10 \mathrm{~mA}$ constant current for $4 \mathrm{~h}$ in a simple undivided cell with carbon cloth as both anode and cathode. The structure of 3aa was further confirmed by X-ray diffraction analysis. Adjusting the current seldom effected the reaction efficiency (Table 1 , entry 2 and 3 ). Using electrolyte like ${ }^{\mathrm{n}} \mathrm{Bu}_{4} \mathrm{NPF}_{6}$ or ${ }^{n} \mathrm{Bu}_{4} \mathrm{NClO}_{4}$ would to some extent decrease the yield (Table 1, entry 4 and 5). Decreasing the volume of ethylene glycol to $0.75 \mathrm{~mL}, 61 \%$ yield of product could still be obtained. If increasing to $2.0 \mathrm{~mL}$, almost the same yield was afforded (Table 1, entry 6 and 7). The effect of electrode materials was also explored. Poor efficiency for the $[4+2]$ annulation was obtained with carbon rod or carbon plate as anode (Table 1, entry 8 and 9). The major side reaction was the decomposition of 3methyl $N$-acetyl indole and no indole dimerization product was detected, which indicated that the electrode with larger surface might enable better reaction efficiency and selectivity. With platinum plate cathode, moderate yield was gained (Table 1, entry 10). Replacing MeCN with DCM did not favor the $[4+2]$ annulation and a majority part of indole disappeared after electrolysis (Table 1, entry 11). No reaction took place without electric current under air atmosphere accompanied by the residue of almost all of starting materials (Table 1, entry 12). Notably, the reaction could be conducted under air atmosphere with a good yield (Table 1, entry 13).

Scope of bis-nucleophiles. To demonstrate the applicability of this transformation, we first evaluated the applicability of various bis-nucleophiles (Fig. 2). With 1-phenylethane-1,2-diol and hexane-1,2-diol, two products were obtained with ratio of 1:1 (3ab and 3ac) in enhanced yield. If ethylene glycol with bigger steric hindrance was applied, the reaction selectivity could be increased to $3.4: 1$ with $82 \%$ yield (3ad). Dearomative $[4+3]$ annulations could also be achieved efficiently from indole and functionalized 1,3-diols (3ae-3ag). 1,3-Diols bearing another rings could afford the spirocyclic compounds in $63 \%$ and $66 \%$ yield, respectively (3ah and 3ai). Moreover, eight-membered ring-fused 2,3-indoline (3aj) was obtained via [6+2] annulation from indole and 1,2-phenylenedimethanol in 50\% yield. We then tested the possibility of forming $\mathrm{C}-\mathrm{N}$ and $\mathrm{C}-\mathrm{S}$ bonds instead of $\mathrm{C}-\mathrm{O}$ bonds. With tert-butyl (2-hydroxyethyl)carbamate as bis-nucleophile, $[4+2]$ dearomative annulation happened regioselectively with $\mathrm{C} 2-\mathrm{O}$ and $\mathrm{C} 3-\mathrm{N}$ bond formation (3ak) owing to the different nucleophilicity. At the same time, we have made much efforts to construct two $\mathrm{C}-\mathrm{N}$ bonds with indoles. After a number of screening, we found that sulfuric diamide could act as a dinitrogen nucleophile to couple with 1a in 58\% yield (3al). The cyclic sulfamide with six or seven-membered ring afforded the desired product in higher yield (3am and 3an). The diamines without the protection of electron-withdrawing substituent could not react with indole under the standard reaction conditions as for the lower oxidation potential. Remarkably, mercaptoethanol and 3-mercaptopropan-1-ol could also couple with indole to afford the six- to seven-membered rings with regioselective $\mathrm{C} 2-\mathrm{O}$ and $\mathrm{C} 3-\mathrm{S}$ bond formation (3ao and 3ap). Interestingly, 58\% yield was obtained for the annulation of ethane-1,2-dithiol with indole to afford bioactive 1,4-dithiane (3aq). 


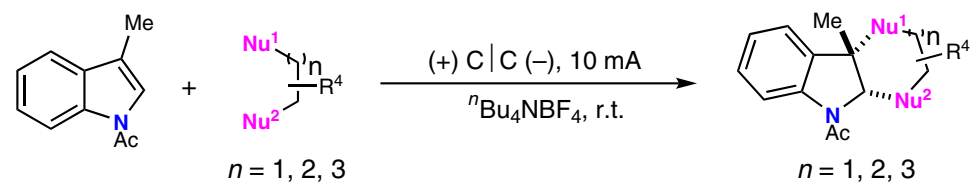

3

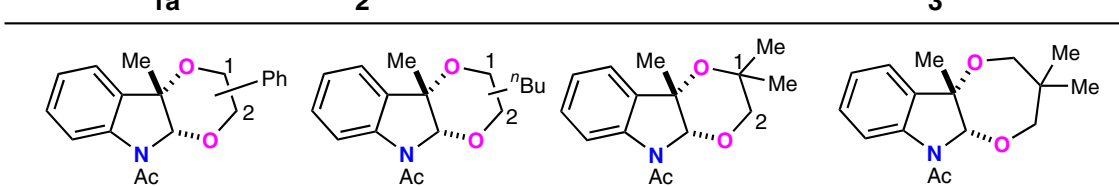

$3 a b, 88 \%(1: 1)$

3ac, $86 \%(1: 1)^{\mathrm{b}}$

3ad, 82\% (3.4:1)<smiles>CN1c2ccccc2[C@@]2(C)OCC(c3ccccc3)CO[C@H]12</smiles>

3af, $73 \%$<smiles>CC12OCc3ccccc3CO[C@H]1N(C(C)(C)C)c1ccccc12</smiles>

3aj, $50 \%$

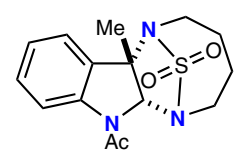

3an, $65 \%$

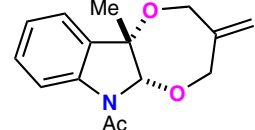

3ag, $71 \%$<smiles>CC(C)(C)OC(=O)N1c2ccccc2[C@@]2(C)NCCO[C@@H]12</smiles>

3ak, $53 \%{ }^{b}$

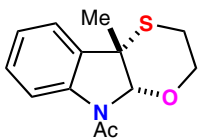

3ao, $66 \% \%^{c}$

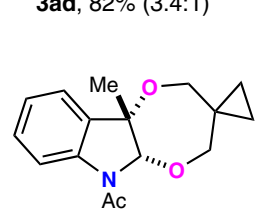

3ah, 63\%<smiles>CN1c2ccccc2[C@@]2(C)NS(=O)(=O)N[C@@H]12</smiles>

3al, 58\%<smiles>CN1c2ccccc2[C@@]2(C)SCCCO[C@H]12</smiles>

3ap, $57 \%{ }^{c}$

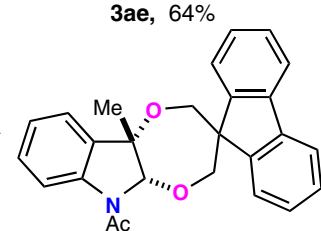

3ai, 66\%

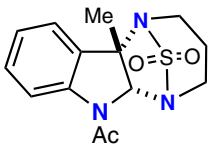

3am, $80 \%$

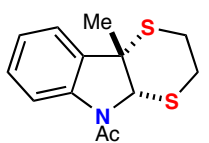

3aq, $58 \%^{\mathrm{C}}$

Fig. 2 Scope of bis-nucleophiles. aReaction conditions: carbon cloth anode $(20 \mathrm{~mm} \times 20 \mathrm{~mm})$, carbon cloth cathode $(20 \mathrm{~mm} \times 20 \mathrm{~mm})$, constant current $=10 \mathrm{~mA}\left(J_{\text {anode }}=2.5 \mathrm{~mA} \mathrm{~cm}^{-2}\right), \mathbf{1 a}(0.50 \mathrm{mmol}), \mathbf{2}(1.2 \mathrm{~mL}$ with liquid glycols, $1.3 \mathrm{~g}$ with solid glycols, 4 eq. with sulfamide, 8 eq. with mercapto containing bis-nucleophiles), ${ }^{n} \mathrm{Bu}_{4} \mathrm{NBF}_{4}(0.30 \mathrm{mmol}), \mathrm{MeCN} / \mathrm{DCM}(5.0 / 4.0 \mathrm{~mL}), \mathrm{N}_{2} .{ }^{b} \mathrm{MeCN}(9.0 \mathrm{~mL}) .{ }^{c} 15 \mathrm{~mA}\left(J_{\text {anode }}=3.75 \mathrm{~mA} \mathrm{~cm}{ }^{-2}\right)$.

Scope of indoles. Next, various indoles were applied to couple with bis-nucleophiles under standard conditions (Fig. 3). The effect of substituents on the benzene ring was firstly scrutinized. Indole rings bearing electron-donating groups and halogens at different positions could afford the annulation product in high efficiency (3aa-3da). Moderate yield was obtained with electronwithdrawing group (3ea). The major side reaction was the decomposition of the indole under the reaction conditions. Free hydroxyl group at phenyl moiety was well tolerated with $65 \%$ yield (3fa). Phenyl substituent at C3 position of indole could also furnish the annulation product in 69\% yield (3ga). $N$-acetyl indoles bearing different C-3 substituents such as simple functionalized alkyl, alkene and phenyl groups were suitable in this oxidative $[4+2]$ dearomative annulation reaction (3ha-3na). Highly functional groups such as alkene, iodide, ester, amide, ketone, azide, and cyano were all well tolerated without hydrolysis or nucleophilic substitution by ethylene glycol. As for the reaction with unsubstituted and 2-substituted indoles (3oa-3ra), moderate yields were obtained, presumably owing to the less-stable reaction intermediates. By using mercaptoethanol as bis-nucleophile, $[4+$ 2] dearomative annulation also proceeded well with different phenyl- and C3 substituted indoles (3sa-3ua). When more sterically hindered 2,3-disubstituted indoles were applied, good reaction efficiency as well as regio- and stereo-selectivity were achieved (3va-3xa). The structure of 3wa was confirmed by X-ray crystallographic analysis.

Scope of benzofurans. Interestingly, benzofurans could also couple with ethylene glycol to achieve the $[4+2]$ dearomative annulation (Fig. 4). Successful reports in the oxidative dearomatization annulation of benzofurans were very limited. This reaction tolerated electron-donating groups, halogens or electronwithdrawing groups at 3 -phenyl rings (5a-5c). Unsubstituted benzofuran could also couple with $2 \mathbf{a}$ in moderate yield and high stereo-selectivity (5f). Enhanced yields were obtained from 2,3disubstituted benzofuran (5d and 5e). Moreover, benzofuranbearing dibenzofuran group could also participate in this transformation $(5 \mathrm{~g})$.

Gram scale synthesis and product transformation. To further explore the utilities of this electrooxidative dearomative annulation for synthesizing polycyclic indolines, $10 \mathrm{mmol} \mathrm{scale} \mathrm{reactions}$ were performed with four kinds of transformation in a simple beaker with $3 \times 3 \mathrm{~cm}^{2}$ carbon cloth as both anode and cathode under air atomosphere. Using $50 \mathrm{~mA}$ high constant current, gram scale of polycyclic indolines could be obtained (Fig. 5a-d). The transformations for heterocycle-fused 2,3-indolines were also conducted. In the presence of $\mathrm{K}_{2} \mathrm{CO}_{3}$ and $\mathrm{MeOH}$ under reflux conditions, $\mathrm{N}$-Ac protected 3aa-delivered compound 6a in $95 \%$ yield (Fig. 6a). Besides, the deprotection of N-Boc group occurred smoothly upon the treatment of 3ak with trifluoroacetic acid, affording $\mathbf{6 b}$ in $82 \%$ yield without affecting N-Ac group (Fig. $6 \mathrm{~b}$ ). The functional group of azide or iodine inside the indoline alkaloids could undergo the click or sonogashi reactions with drug molecules to afford the product $\mathbf{6 c}$ and $\mathbf{6 d}$, respectively (Fig. 6c, d).

\section{Discussion}

Since the method has been established, efforts were then paid to understand the mechanism for this selectively oxidative dearomatization reaction. First, cyclic voltammetry experiments of 3methyl $N$-acetyl indole (1a), ethane-1,2-diol (2a), tert-butyl (2hydroxyethyl)carbamate (2k), and sulfuric diamide (2l) were 

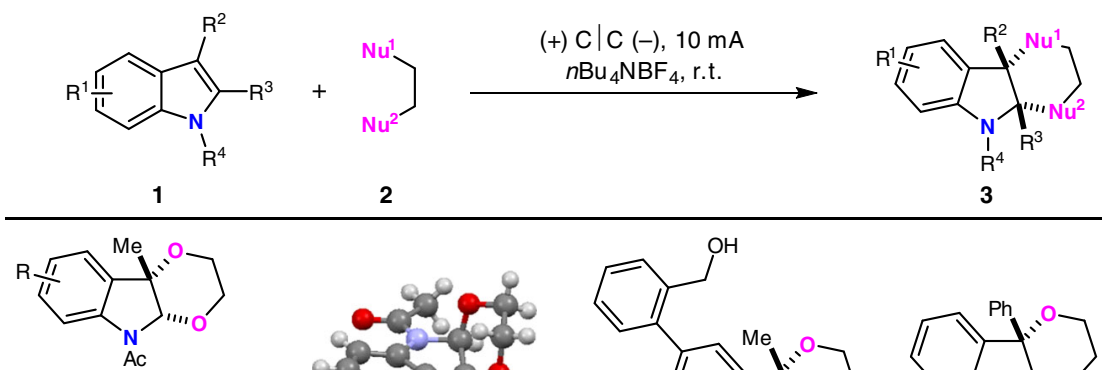

3aa, $R=H, 75 \%$

3ba, $R=5-I, 72 \%$

3ca, $R=5-O M e, 74 \%$

3da, $\mathrm{R}=6-\mathrm{Cl}, 73 \%$

3ea, $\mathrm{R}=5-\mathrm{CF}_{3}, 45 \%$

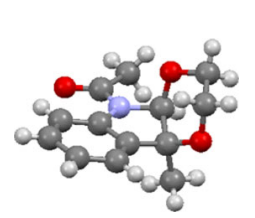

3aa

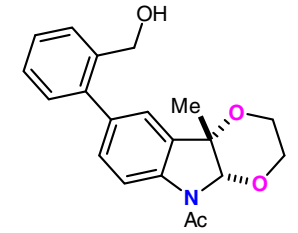

3fa, $65 \%$

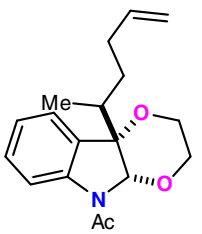

3la, $64 \%$

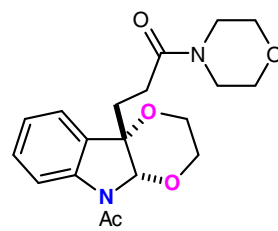

3ka, 86\%

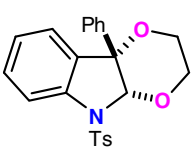

3ga, $69 \%$<smiles>[R]CC[C@]12OCCO[C@H]1N(C)c1ccccc12</smiles>

3ha, $\mathrm{R}=\mathrm{CH}_{2} \mathrm{Br}, 74 \%$ 3ia, $\mathrm{R}=\mathrm{N}_{3}, 72 \%$ 3ja, R = NPhth, 70\%<smiles>C#CO[C@@H]1OCCO[C@@H]2N(C)c3ccccc3[C@@]12C(C)c1ccc(C#N)cc1</smiles>

3na, $72 \%$

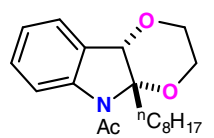

3ra, $58 \%$

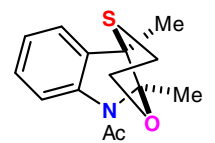

3va, $68 \%$

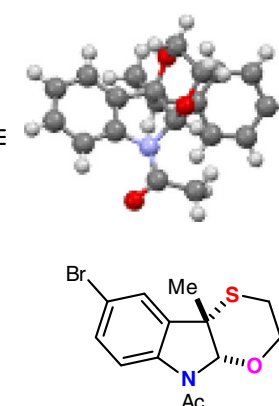

3sa, $71 \%{ }^{c}$

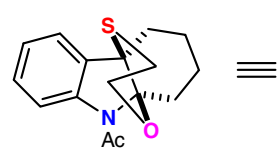

3wa, $61 \%$

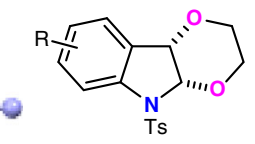

3oa, $\mathrm{R}=5-\mathrm{Br}, 58 \%$

3pa, $R=6-$ COOMe, $55 \%$<smiles>CN1c2ccccc2[C@@]2(C3CCOCC3)SCCO[C@H]12</smiles>

3ta, $73 \%$ c

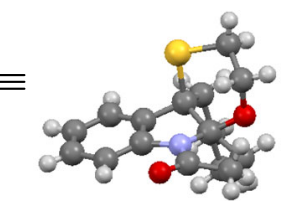<smiles>N#CN1c2ccccc2[C@@]2(C3CCC4(C3)OCCO4)OCCO[C@H]12</smiles>

3ma, $65 \%{ }^{b}$<smiles>CN1c2ccc(Cl)cc2[C@@H]2OCCO[C@]21C</smiles>

3qa, $63 \%$<smiles>CC(=O)OCCC[C@]12SCCO[C@H]1N(C)c1ccccc12</smiles>

3ua, $76 \%$ c

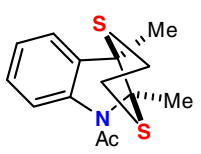

3xa, $52 \%{ }^{c}$

Fig. 3 Scope of indoles. aReaction conditions: carbon cloth anode $(20 \mathrm{~mm} \times 20 \mathrm{~mm})$, carbon cloth cathode $(20 \mathrm{~mm} \times 20 \mathrm{~mm})$, constant current $=10 \mathrm{~mA}$ $\left(J_{\text {anode }}=2.5 \mathrm{~mA} \mathrm{~cm}^{-2}\right), \mathbf{1}(0.50 \mathrm{mmol}), \mathbf{2}\left(1.2 \mathrm{~mL}\right.$ with liquid glycols, $1.3 \mathrm{~g}$ with solid glycols, 8 eq. with mercapto containing bis-nucleophiles), ${ }^{n B u_{4}} \mathrm{NBF}_{4}$ $(0.30 \mathrm{mmol}), \mathrm{MeCN}(9.0 \mathrm{~mL}), \mathrm{N}_{2}$. Isolated yields were shown. ${ }^{b}$ Ketone and ethylene glycol condensation. ${ }^{\mathrm{C}} \mathrm{MeCN} / \mathrm{DCM}=5 / 4 \mathrm{~mL}$ as co-solvent, $15 \mathrm{~mA}$ $\left(J_{\text {anode }}=3.75 \mathrm{~mA} \mathrm{~cm}^{-2}\right)$.

conducted (Fig. 7a). 3-Methyl $\mathrm{N}$-acetyl indole started to be oxidized at $\sim 1.20 \mathrm{~V}$. By contrast, the oxidation onset of ethane-1,2diol (2a), tert-butyl (2-hydroxyethyl)carbamate (2k), and sulfuric diamide (2l) was at $\sim 1.86 \mathrm{~V}$, so 1 a would be oxidized before $\mathbf{2 a}$, $\mathbf{2 k}$ and $\mathbf{2 l}$. Then, the controlled potential electrolysis was carried out. If controlling the potential of anode to $0.8 \mathrm{~V}$ where both of the substrates could not be oxidized, no product was detected (Fig. 7b). If controlling the potential of anode to $1.4 \mathrm{~V}$ where only 1a could be oxidized, 62\% yield of product was afforded (Fig. 7c). Meanwhile, $\mathrm{P}(\mathrm{OEt})_{3}$ was added into the standard reaction to explore the existence of indole radical cation intermediate. An indole phosphorylation product could be isolated in $6 \%$ yield and $69 \%$ yield of $[4+2]$ annulation product was obtained (Fig. $7 \mathrm{~d}$ ). The oxidation peak of $\mathrm{P}(\mathrm{OEt})_{3}$ was observed at $1.9 \mathrm{~V}$, which was higher than that of indoles, so $\mathrm{P}(\mathrm{OEt})_{3}$ would not be oxidized under the standard reaction conditions. The large amount of ethylgloyl had better capacity of capturing in situ generated indole radical cation than $\mathrm{P}(\mathrm{OEt})_{3}$, which led to the low yield of phosphorylation product. These results indicated that the anodic oxidation of 3-methyl $\mathrm{N}$-acetyl indole might initiate this transformation, albeit the ethane-1,2-diol (2a), tert-butyl (2-hydroxyethyl)carbamate (2k) and sulfuric diamide (2l) have not been oxidized and just acted as bis-nucleophiles. In-depth analysis of the regioselectivity issue in the case of $\mathbf{2 k}$, which contained both $\mathrm{OH}$ and $\mathrm{NH}$ nucleophilic group, $\mathrm{C} 2-\mathrm{O}$ and $\mathrm{C} 3-\mathrm{N}$ bond formation happened selectively with 1 a. We reasoned that the radical of indole radical cation mainly delocalized at $\mathrm{C} 3$ position with the stablization of phenyl group, and cation mainly existed at C2 position via the formation of imine. Since the nucloephilicity of $\mathrm{OH}$ is stronger than that of $\mathrm{NHBoc}$, the nucleophilic attack of $\mathrm{OH}$ happened first at $\mathrm{C} 2$ position of indole radical cation to afford the benzylic carbon radical. The second oxidation of benzylic carbon radical gave carbon cation, followed by the intramolecular attack of $\mathrm{NHBoc}$ to form $\mathrm{C}-\mathrm{N}$ bond at $\mathrm{C} 3$ position.

In addition, in-operando infrared spectroscopy analysis of the electrooxidative dearomative annulation benween $1 \mathbf{a}$ and $2 \mathbf{a}$ by 


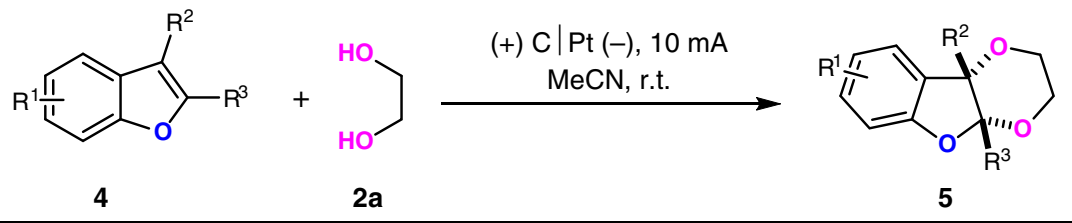

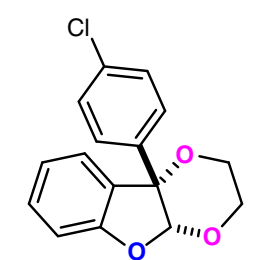

5a, $52 \%$<smiles>COc1ccc([C@]23OCCO[C@H]2Oc2ccccc23)cc1</smiles>

5b, $55 \%$<smiles>FC(F)(F)c1ccc([C@]23OCCO[C@H]2Oc2ccccc23)cc1</smiles>

5c, $51 \%^{\mathrm{b}}$

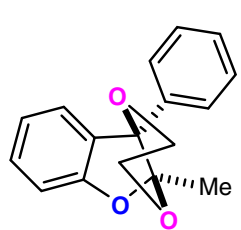

5d, $71 \%$<smiles>O=C1Oc2ccccc2C12CCc1ccccc1OC21CCCC1</smiles>

$5 e, 87 \%$<smiles>c1ccc2c(c1)O[C@@H]1OCCO[C@H]21</smiles>

5f, $36 \%$

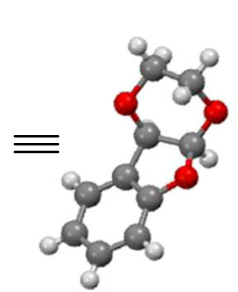

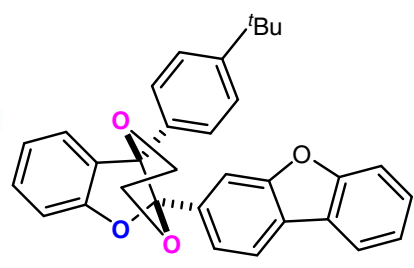

$5 \mathrm{~g}, 58 \%$

Fig. 4 Scope of benzofurans. aReaction conditions: graphite rod anode $(\phi 6 \mathrm{~mm})$, platinum plate cathode $(15 \mathrm{~mm} \times 15 \mathrm{~mm} \times 0.3 \mathrm{~mm})$, constant current $=$ $10 \mathrm{~mA}\left(J_{\text {anode }} \approx 11.2 \mathrm{~mA} \mathrm{~cm}^{-2}\right), 4(0.30 \mathrm{mmol}), \mathbf{2 a}(1.0 \mathrm{~mL}),{ }^{n} \mathrm{Bu}_{4} \mathrm{NBF}_{4}(0.30 \mathrm{mmol}), \mathrm{MeCN}(5.0 \mathrm{~mL}), 4 \mathrm{~h}, \mathrm{~N}_{2} .{ }^{b} 20 \mathrm{~mA}\left(J_{\text {anode }} \approx 22.4 \mathrm{~mA} \mathrm{~cm}^{-2}\right)$.<smiles>Cc1cn(C)c2ccccc12</smiles>

$10 \mathrm{mmol}$<smiles>Cc1cn(C)c2ccccc12</smiles>

$10 \mathrm{mmol}$<smiles>Cc1cn(C)c2ccccc12</smiles>

$10 \mathrm{mmol}$<smiles>Cc1cn(C)c2ccccc12</smiles>

$10 \mathrm{mmol}$<smiles>OCCO</smiles>

$(+) \mathrm{C} \mid \mathrm{C}(-), 50 \mathrm{~mA}$<smiles>[131IH]</smiles>

$(+) \mathrm{C} \mid \mathrm{C}(-), 50 \mathrm{~mA}$<smiles>OCC(CO)c1ccccc1</smiles><smiles>CC[13CH]C</smiles><smiles>OCCS</smiles>

$(+) \mathrm{C} \mid \mathrm{C}(-), 50 \mathrm{~mA}$

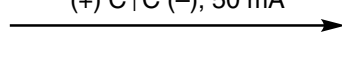

$(+) \mathrm{C} \mid \mathrm{C}(-), 50 \mathrm{~mA}$<smiles>CN1c2ccccc2[C@@]2(C)OCCO[C@H]12</smiles>

3 aa

$1.7 \mathrm{~g}, 73 \%$<smiles>CN1c2ccccc2[C@@]2(C)OCC(c3ccccc3)CO[C@@H]12</smiles>

3af

$2.0 \mathrm{~g}, 62 \%$<smiles>CC(C)N1c2ccccc2[C@@]2(C)SCCO[C@H]12</smiles>

3 ao $1.5 \mathrm{~g}, 62 \%$<smiles></smiles>

3am

$2.1 \mathrm{~g}, 69 \%$

Fig. 5 Large-scale synthesis. a Gram scale synthesis of 3aa. b Gram scale synthesis of 3af. c Gram scale synthesis of 3ao. d Gram scale synthesis of 3am.

react-IR technology did not show any sign for an induction period (see Supplementary Fig. 1a). Kinetic studies of this process were performed by detecting the initial reaction rate with different current, different loading of 3-methyl $\mathrm{N}$-acetyl indole (1a) and ethylene glycol (2a). It was found that the initial rate increased in a linear fashion with increasing current (see Supplementary Fig. 1b). As for the kinetic profiles of substrates, the first-order dependencies at low concentration of $\mathbf{1 a}$ was observed 
a

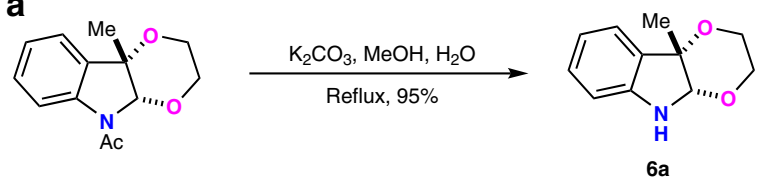

b

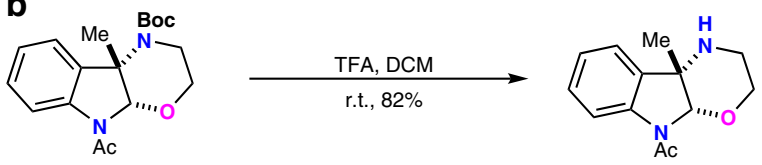

$6 b$

C<smiles>CN1c2ccccc2C2(CCN)OCCO[C@H]12</smiles><smiles>CC(=O)c1ccc(S(=O)(=O)N(C(C)C)C(C)C)cc1</smiles><smiles>C#Cc1ccc(COC(=O)O)cc1</smiles>

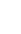

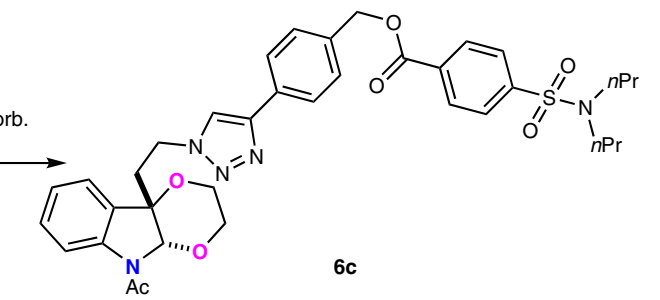

d<smiles>C[C@]12OCC[OH+][C@H]1Nc1ccc(I)cc12</smiles><smiles>C#Cc1ccc2c(c1)CC[C@@H]1[C@@H]2CC[C@]2(C)C(=O)CC[C@@H]12</smiles>
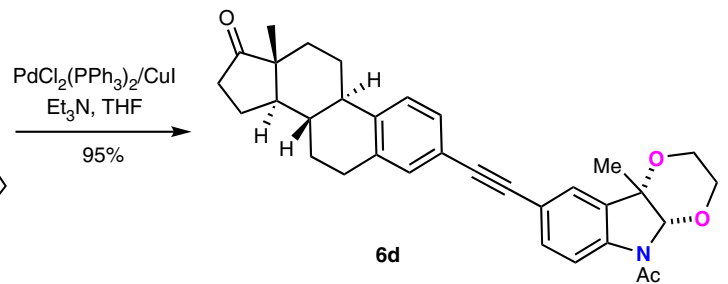

Fig. 6 Product transformations. a Deprotection of 3aa. b Deprotection of 3ak. c Transformation of azide group in 3ia. d Transformation of iodine group in 3 ba.

and the reaction rate was saturated at high concentrations (see Supplementary Fig. 1c). This might be attributed to the current controlled result at high concentration of 1a. However, the initiate rate constants showed to be independent of the concentration of $\mathbf{2 a}$ (see Supplementary Fig. 1d). Combining these kinetic behaviors with mechanism study above, it suggested that the anodic oxidation of $\mathbf{1 a}$ to indole radical cation was the ratedetermining step.

Next, cyclic voltammograms of 3-methyl $\mathrm{N}$-acetyl indole (1a), 2-mercaptoethanol (2o), and ethane-1,2-dithiol (2q) were measured (Fig. 8a). 3-Methyl $N$-acetyl indole (1a), mercaptoethanol (2o), and ethane-1,2-dithiol (2q) all started to be oxidized at about $1.20 \mathrm{~V}$. These results indicated that 3-methyl $\mathrm{N}$-acetyl indole (1a), mercaptoethanol (2o), and ethane-1,2-dithiol (2q) might all be oxidized at the same time during the electrolysis to generate reactive intermediates. As both of the substrates could be oxidized, electron paramagnetic resonance (EPR) experiments were performed to explore the radical species with adding free radical spin trapping agent DMPO (5,5-dimethyl-1-pyrroline $\mathrm{N}$ oxide) into the reaction system. When DMPO was added to the reaction of mercaptoethanol (2o) under the standard conditions, an obvious EPR signal was observed, which was suggested as an alkyl sulfur radical. This radical was quickly trapped by DMPO to afford a more stable radical $(g=2.00688, \mathrm{AN}=\mathrm{AH}=13.8 \mathrm{G})$ (Fig. 8b). Next, when DMPO was added to the reaction mixture of $\mathbf{1 a}$ and 2o, the same radical signal was observed, which further proved the existence of sulfur-center radical during the reaction of $\mathbf{1 a}$ and $2 \mathbf{o}$ (Fig. 8c). On the other hand, if adding six equivalent of triethyl phosphite into the standard reaction, $12 \%$ yield of [ $4+$ 2] annulation product could be gained. At the same time, an indole phosphorylation product $6 \mathrm{e}$ could be isolated in $22 \%$ yield, which proved the existence of indole radical cation intermediate (Fig. 8d). Then, the controlled potential electrolysis was carried out. Controlling the potential of anode to $1.4 \mathrm{~V}$ where both of $\mathbf{1 a}$ and 20 could be oxidized, 55\% corresponding product was obtained (Fig. 8e). These results indicated that the reaction might go through the cross-coupling of sulfur radical with indole cation radical intermediate. Subsequent intramolecular annulation afforded the $[4+2]$ dearomative annulation product. As for the regioselective issue in the case of 1 a with 20 where $\mathrm{C}-\mathrm{S}$ bond formed at $\mathrm{C} 3$ position and $\mathrm{C}-\mathrm{O}$ bond formed at $\mathrm{C} 2$ position selectively, we speculated that the reaction proceeded through the cross-coupling of sulfur radical with indole radical cation at C3 position where the radical species was stabilized by phenyl group. Subsequent intramolecular nucleophilic attack of $\mathrm{OH}$ to imine cation afforded the corresponding product.

Then, kinetic studies for the dearomative annulation of 1 a with 2o were performed to determine the order of reaction components in this dearomative annulation with different loading of 3-methyl $\mathrm{N}$-acetyl indole (1a) and mercaptoethanol (2o). As for the kinetic profiles of the substrates, the first-order dependencies of 1a was observed (see Supplementary Fig. 2a). However, the initiate rate was almost invariant when using different concentrations of $\mathbf{2 0}$, indicating that the reaction rate is independent of the concentration of 20 (see Supplementary Fig. 2b). Similar to the kinetic behavior of 1 a with $2 \mathrm{a}$, the results suggested that the anodic oxidation of 1a into indole radical cation was the slowest step throughout the transformation, and the processes of anodic oxidation of S-H into sulfur radical, radical-radical cross-coupling and cascade nucleophilic attack might be relative fast steps.

Based on the above experiment results, a plausible mechanism for these electrooxidative dearomatization annulations was shown in Fig. 9. In the first step, 1a would be oxidized at carbon anode to generate a radical cation I where radical mostly lied at C3 position with stablization of phenyl group and cation mostly lied at $\mathrm{C} 2$ position stabilized by the formation of imine cation. This reactive intermediate could undergo two different transformations by making use of radical and cation centers. If 

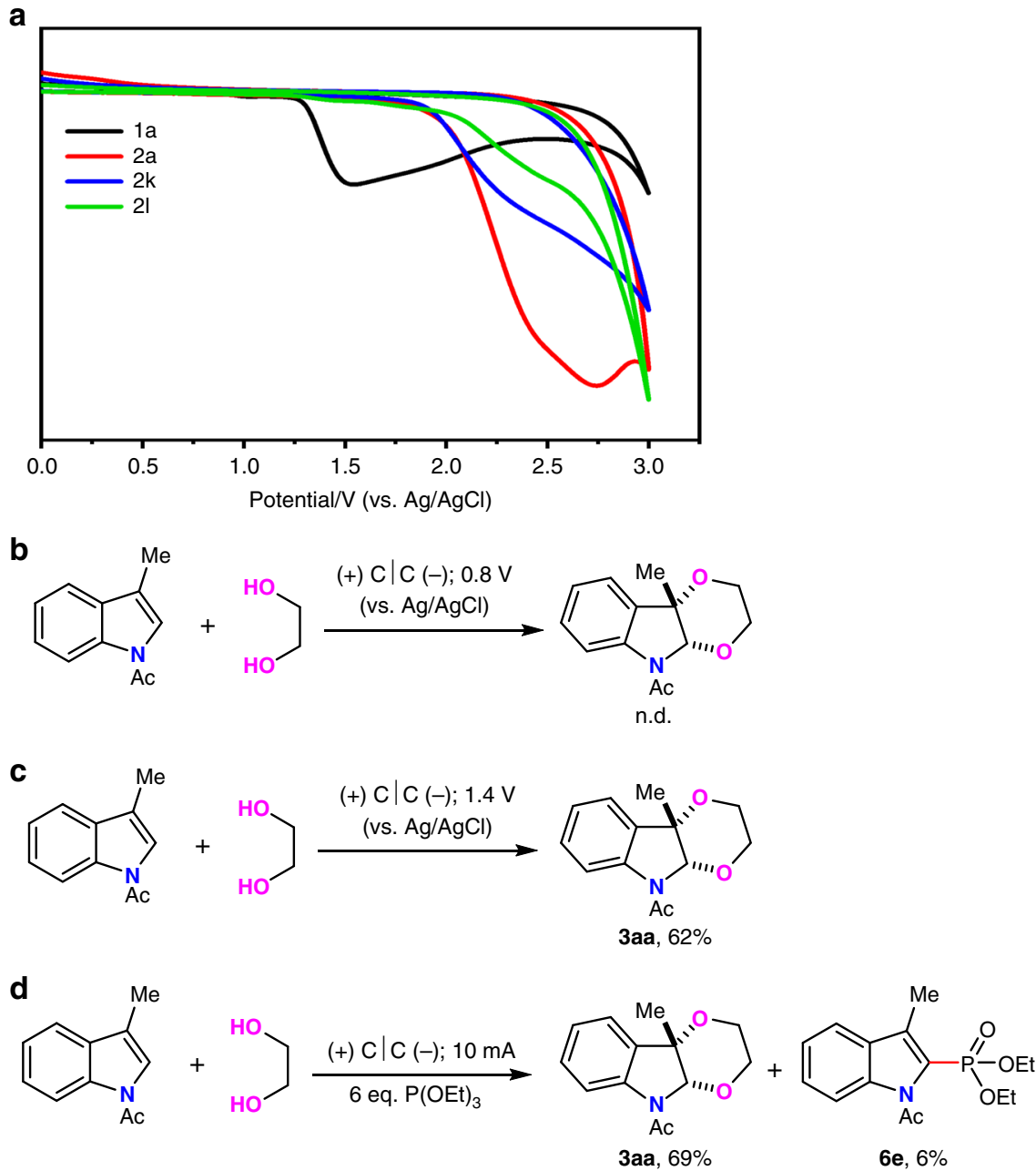

Fig. 7 Mechanism study for the reaction of 1a with 2a. a Cyclic voltammograms on a glassy carbon electrode $(\phi 3 \mathrm{~mm})$ at $0.1 \mathrm{Vs}{ }^{-1}$ under nitrogen. Black line, 3-methyl $\mathrm{N}$-acetyl indole (1a); red line, ethane-1,2-diol (2a); blue line, tert-butyl (2-hydroxyethyl)carbamate (2k); green line, sulfuric diamide (2I). b Potential controlled electrolysis to $0.8 \mathrm{~V}$ (vs $\mathrm{Ag} / \mathrm{AgCl}$ ). c Potential controlled electrolysis to $1.4 \mathrm{~V}$ (vs $\mathrm{Ag} / \mathrm{AgCl}$ ). d Radical cation trapping experiment by $\mathrm{P}(\mathrm{OEt})_{3}$.

ethane-1,2-diol (2a) was applied as bis-nucleophile, first nucleophilic attack at the C2 position of I afforded benzylic carbon radical intermediate II. The oxidation of benzylic carbon radical gave carbon cation, followed by the intramolecular attack of $\mathrm{OH}$ to form $\mathrm{C}-\mathrm{O}$ bond at $\mathrm{C} 3$ position. If bis-nucleophiles contains mercaptan, single-electron oxidation of mercaptan could generate sulfur-center radical in the meantime. Radical-radical crosscoupling between indole radical cation and sulfur radical at $\mathrm{C} 3$ position afforded intermediate V. Subsequently, the intramolecular attack of nucleophilic side chain to iminium moiety yielded the corresponding polycyclic indolines with excellent cis-diastereo-selectivity. The processes of radical-radical cross-coupling and nucleophilic attack might also happen at the same time.

In summary, we have developed an electrochemical method for the oxidative dearomatization annulation of indole and benzofuran derivatives. Under undivided electrolytic conditions, $[3+$ $2],[4+2],[5+2]$, as well as $[6+2]$ annulation happened regioand setero-selectively with $\mathrm{O}-, \mathrm{N}-, \mathrm{S}$-nucleophilic groups. A series of highly functionalized five to eight-membered heterocycle-2,3fused indolines and dihydrobenzofurans were afforded, which are typically unattainable under thermal conditions. Notably, highly active functional groups such as iodide, hydroxyl, alkene, azide, ester, amide, cyano, carbonyl groups, etc. could all be well tolerated after electrolysis. A detailed mechanistic survey, including cyclic voltammetry, EPR, radical trapping experiments, and kinetic studies have been presented. These results demonstrate that anodic oxidation-induced indole radical cation has a vital role in these transformations and this process is the ratedeterming step. The dearomative annulation of indoles with diols is believed to proceed through the two-step nucleophilic attack, whereas the annulation with mercapto group containing bisnucleophiles proceeds through the radical-radical cross-coupling of indole radical cation and sulfur radical with subsequent nucleophilic attack. The unique reaction pathways have resulted in the high regio- and diastereo-selectivity. Finally, we believe this powerful strategy would stimulate broad interests in the journey of natural product total synthesis.

\section{Methods}

General procedure for the reaction of $1 \mathbf{a}$ with $\mathbf{2 a}$. In an oven-dried undivided three-necked bottle $(25 \mathrm{~mL})$ equipped with a stir bar, $N$-acetyl indole $(0.5 \mathrm{mmol})$, $n \mathrm{Bu}_{4} \mathrm{NBF}_{4}(98.7 \mathrm{mg}, 0.30 \mathrm{mmol})$, and MeCN/ethane-1,2-diol $(9.0 \mathrm{~mL} / 1.2 \mathrm{~mL})$ were combined and added. The bottle was equipped with carbon cloths $(20 \mathrm{~mm} \times$ $20 \mathrm{~mm}$ ) as both the anode and cathode and then charged with nitrogen. Then the electrolysis system was stirred at a constant current of $10 \mathrm{~mA}$ at room temperature until the complete consumption of $\mathrm{N}$-acetyl indole (detected by thin-layer chromatography; TLC). When the reaction finished, the reaction mixture was washed with water and extracted with diethyl ether $(10 \mathrm{~mL} \times 3)$. The organic layers were combined, dried over $\mathrm{Na}_{2} \mathrm{SO}_{4}$, and concentrated. The pure product was obtained by flash column chromatography on silica gel (petroleum: ethyl acetate $=7: 1$ ). Full 
a

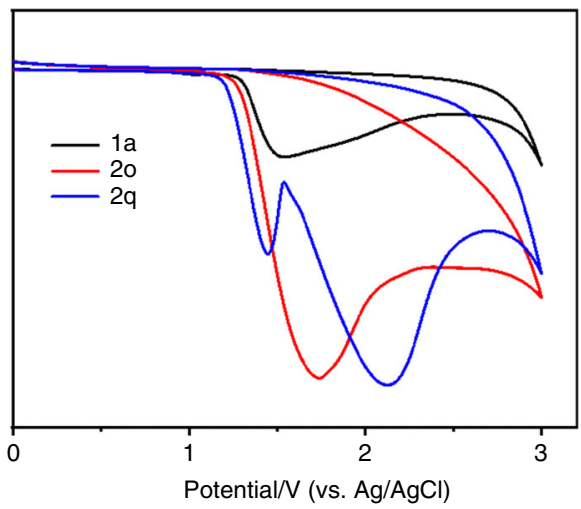

b

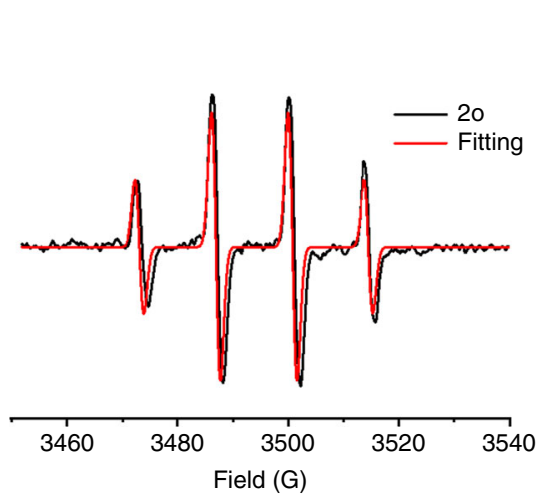

C

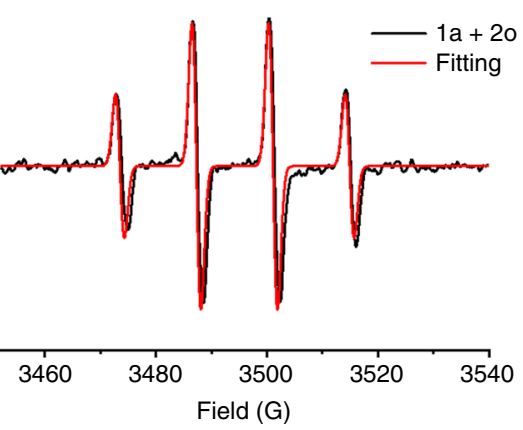

\section{d}<smiles>Cn1cc([N+](=O)[O-])c2ccccc21</smiles><smiles>OCCS</smiles>

$\underset{6 \text { eq. }}{\stackrel{(+)}{ }(\mathrm{CEt})_{3}}$<smiles>CN1c2ccccc2[C@@]2(C)SCCO[C@@H]12</smiles><smiles>CCOP(=O)(OCC)c1c(C)c2ccccc2n1C</smiles>

3ao, $12 \%$ yield

$6 e, 22 \%$ yield

e<smiles>Cc1cn([Tl])c2ccccc12</smiles><smiles>C[C@]12SCCO[C@H]1N([14CH3])c1ccccc12</smiles>

3ao, $55 \%$ yield

Fig. 8 Mechanism study for the reaction of 1a with 2o. a Cyclic voltammograms on a glassy carbon electrode $(\phi 3 \mathrm{~mm})$ at $0.1 \mathrm{Vs}{ }^{-1}$ under nitrogen. Black line, 3-methyl $\mathrm{N}$-acetyl indole (1a); red line, mercaptoethanol (20); blue line, ethane-1,2-dithiol (2q). $\mathbf{b}$ EPR measurements of $\mathbf{2 0}$ in the presence of DMPO under constant current conditions for 6 min. $\mathbf{c}$ EPR measurements of $\mathbf{1 a}$ and $\mathbf{2 0}$ in the same conditions. $\mathbf{d}$ Radical cation trapping experiment by $\mathrm{P}(\mathrm{OEt})_{3}$. $\mathbf{e}$ Controlled potential electrolysis.

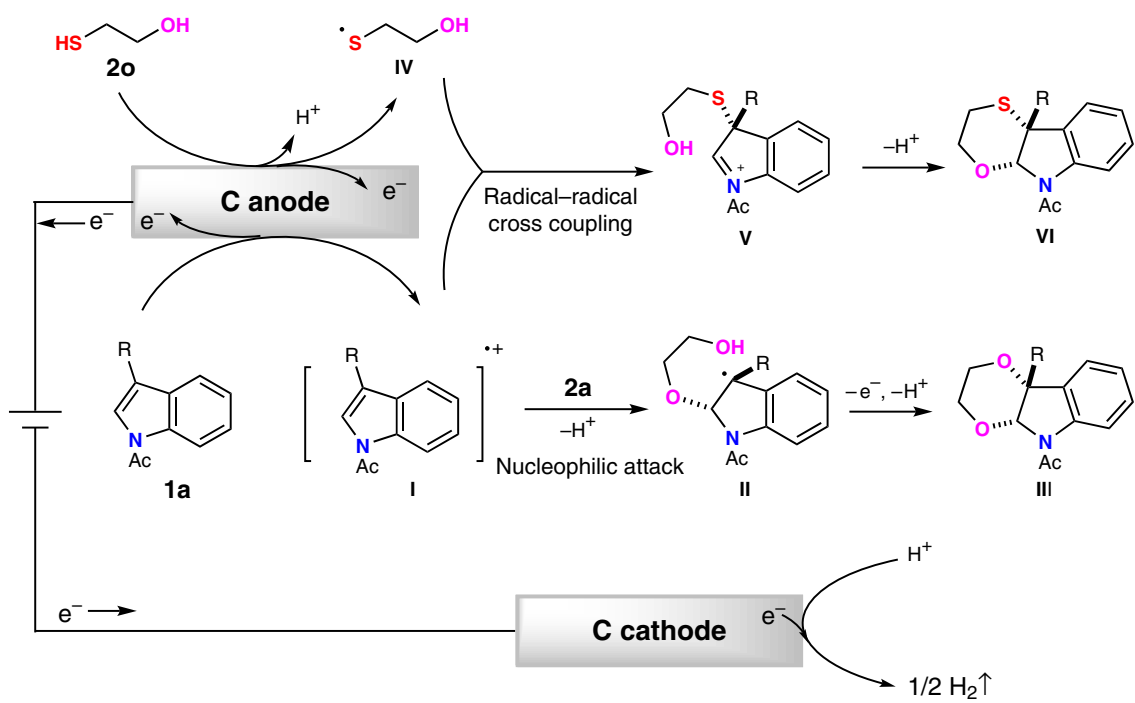

Fig. 9 Plausible mechanism for the dearomative annulation of indole. The plausible mechanism involves anodic oxidation of indole to generate indole radical cation. Two steps of nucleophilic attack by ethylene glycol accompanied with an oxidation process would afford product 3aa. On the other hand, radical-radical cross-coupling with in situ generated sulfur radical and subsequent intramolecular nucleophilic attack would furnish product $\mathbf{3 a o}$

experimental details and characterization of the compounds are given in the Supplementary Information.

General procedure for the reaction of 1a with 20. In an oven-dried undivided three-necked bottle $(25 \mathrm{~mL})$ equipped with a stir bar, $N$-acetyl indole $(0.5 \mathrm{mmol})$, $n \mathrm{Bu}_{4} \mathrm{NBF}_{4}$ (98.7 mg, $\left.0.3 \mathrm{mmol}\right)$, 20 (8 eq.), and MeCN/DCM $(5.0 \mathrm{~mL} / 4 \mathrm{~mL})$ were combined and added. The bottle was equipped with carbon cloths $(20 \mathrm{~mm} \times$ $20 \mathrm{~mm}$ ) as both the anode and cathode and then charged with nitrogen. Then the electrolysis system was stirred at a constant current of $15 \mathrm{~mA}$ at room temperature until the complete consumption of $N$-acetyl indole (detected by TLC). When the reaction finished, the reaction mixture was washed with water and extracted with 
diethyl ether $(10 \mathrm{~mL} \times 3)$. The organic layers were combined, dried over $\mathrm{Na}_{2} \mathrm{SO}_{4}$, and concentrated. The pure product was obtained by flash column chromatography on silica gel (petroleum: ethyl acetate $=7: 1$ ). Full experimental details and characterization of the compounds are given in the Supplementary Information.

\section{Data availability}

The X-ray crystallographic coordinates for structures reported in this article have been deposited at the Cambridge Crystallographic Data Centre (CCDC), under deposition number CCDC 1963165 (3aa), CCDC 1963166 (3na'), CCDC 1963167 (3wa), CCDC 1963168 (5f), CCDC 1963169 (3na). The data can be obtained free of charge from The Cambridge Crystallographic Data Centre [http://www.ccdc.cam.ac.uk/data_request/cif]. The data supporting the findings of this study are available within the article and its Supplementary Information files. Any further relevant data are available from the authors on request

Received: 4 August 2019; Accepted: 29 November 2019; Published online: 07 January 2020

\section{References}

1. Zhuo, C.-X., Zheng, C. \& You, S.-L. Transition-metal-catalyzed asymmetric allylic dearomatization reactions. Acc. Chem. Res. 47, 2558-2573 (2014).

2. Fan, L., Liu, J., Bai, L., Wang, Y. \& Luan, X. Rapid assembly of diversely functionalized spiroindenes by a three-component palladium-catalyzed $\mathrm{C}-\mathrm{H}$ amination/phenol dearomatization domino reaction. Angew. Chem. Int. Ed. 56, 14257-14261 (2017).

3. Wu, W.-T., Zhang, L. \& You, S.-L. Catalytic asymmetric dearomatization (CADA) reactions of phenol and aniline derivatives. Chem. Soc. Rev. 45, 1570-1580 (2016).

4. Wertjes, W. C., Southgate, E. H. \& Sarlah, D. Recent advances in chemical dearomatization of nonactivated arenes. Chem. Soc. Rev. 47, 7996-8017 (2018).

5. Chen, J.-B. \& Jia, Y.-X. Recent progress in transition-metal-catalyzed enantioselective indole functionalizations. Org. Biomol. Chem. 15, 3550-3567 (2017).

6. Roche, S. P., Youte Tendoung, J.-J. \& Tréguier, B. Advances in dearomatization strategies of indoles. Tetrahedron 71, 3549-3591 (2015).

7. Crich, D. \& Banerjee, A. Chemistry of the hexahydropyrrolo[2,3-b]indoles: configuration, conformation, reactivity, and applications in synthesis. Acc. Chem. Res. 40, 151-161 (2007).

8. Austin, J. F., Kim, S.-G., Sinz, C. J., Xiao, W.-J. \& MacMillan, D. W. C. Enantioselective organocatalytic construction of pyrroloindolines by a cascade addition-cyclization strategy: Synthesis of (-)-flustramine b. Proc. Natl Acad. Sci. 101, 5482 (2004).

9. Steven, A. \& Overman, L. E. Total synthesis of complex cyclotryptamine alkaloids: Stereocontrolled construction of quaternary carbon stereocenters. Angew. Chem. Int. Ed. 46, 5488-5508 (2007).

10. Bandini, M. \& Eichholzer, A. Catalytic functionalization of indoles in a new dimension. Angew. Chem. Int. Ed. 48, 9608-9644 (2009).

11. Hua, T.-B., Xiao, C., Yang, Q.-Q. \& Chen, J.-R. Recent advances in asymmetric synthesis of 2-substituted indoline derivatives. Chin. Chem. Lett. https://doi. org/10.1016/j.cclet.2019.07.015 (2019).

12. Zhang, D., Song, H. \& Qin, Y. Total synthesis of indoline alkaloids: a cyclopropanation strategy. Acc. Chem. Res. 44, 447-457 (2011).

13. Miller, K. A., Tsukamoto, S. \& Williams, R. M. Asymmetric total syntheses of $(+)$ - and (-)-versicolamide b and biosynthetic implications. Nat. Chem. 1, 63 (2009).

14. Zuo, Z. \& Ma, D. Enantioselective total syntheses of communesins a and b. Angew. Chem. Int. Ed. 50, 12008-12011 (2011).

15. Bartoli, G., Bencivenni, G. \& Dalpozzo, R. Organocatalytic strategies for the asymmetric functionalization of indoles. Chem. Soc. Rev. 39, 4449-4465 (2010).

16. Yang, J., Wu, H., Shen, L. \& Qin, Y. Total synthesis of ( \pm )-communesin F. J. Am. Chem. Soc. 129, 13794-13795 (2007).

17. Jung, M. E. \& Slowinski, F. Rhodium-catalyzed decomposition of indolesubstituted $\alpha$-diazo- $\beta$-keto esters: Three different reactions based on indole oxidation state. Tetrahedron Lett. 42, 6835-6838 (2001).

18. Padwa, A. \& Price, A. T. Tandem cyclization-cycloaddition reaction of rhodium carbenoids as an approach to the aspidosperma alkaloids. J. Org. Chem. 60, 6258-6259 (1995).

19. Zhu, M., Zheng, C., Zhang, X. \& You, S.-L. Synthesis of cyclobutane-fused angular tetracyclic spiroindolines via visible-light-promoted intramolecular dearomatization of indole derivatives. J. Am. Chem. Soc. 141, 2636-2644 (2019).

20. Chataigner, I., Hess, E., Toupet, L. \& Piettre, S. R. Activation of the dienophilicity of indoles in normal electron demand $[4+2]$ cycloadditions under high pressure. Org. Lett. 3, 515-518 (2001).
21. Zheng, C. et al. The enantioselective, organocatalyzed diels-alder reaction of 2 -vinylindoles with $\alpha, \beta$-unsaturated aldehydes: An efficient route to functionalized tetrahydrocarbazoles. Chem. Eur. J. 16, 5853-5857 (2010).

22. Menozzi, C., Dalko, P. I. \& Cossy, J. Concise synthesis of the ( \pm )-nbdesmethyl-meso-chimonanthine. Chem. Commun. 38, 4638-4640 (2006).

23. Li, T.-R., Lu, L.-Q., Wang, Y.-N., Wang, B.-C. \& Xiao, W.-J. Divergent synthesis of polycyclic indolines: copper-catalyzed cascade reactions of propargylic carbamates and indoles. Org. Lett. 19, 4098-4101 (2017).

24. Bai, L. et al. Palladium/norbornene-catalyzed $\mathrm{C}-\mathrm{H}$ alkylation/alkyne insertion/indole dearomatization domino reaction: assembly of spiroindolenine-containing pentacyclic frameworks. Angew. Chem. Int. Ed. 57, 5151-5155 (2018).

25. Tu, H.-F., Zhang, X., Zheng, C., Zhu, M. \& You, S.-L. Enantioselective dearomative prenylation of indole derivatives. Nat. Catal. 1, 601-608 (2018).

26. Cheng, H.-G. et al. Highly enantioselective friedel-crafts alkylation/nhemiacetalization cascade reaction with indoles. Angew. Chem. Int. Ed. 52, 3250-3254 (2013).

27. Denizot, N. et al. Bioinspired direct access to benzofuroindolines by oxidative $[3+2]$ annulation of phenols and indoles. Org. Lett. 16, 5752-5755 (2014).

28. Liu, Q. et al. A trans diacyloxylation of indoles. Chem. Commun. 48, 3239-3241 (2012).

29. Zhang, M., Duan, Y., Li, W., Cheng, Y. \& Zhu, C. Visible-light-induced aerobic dearomative reaction of indole derivatives: access to heterocycle fused or spirocyclo indolones. Chem. Commun. 52, 4761-4763 (2016).

30. Depew, K. M. et al. Total synthesis of 5-N-acetylardeemin and amauromine: practical routes to potential mdr reversal agents. J. Am. Chem. Soc. 121, 11953-11963 (1999).

31. Han, L., Liu, C., Zhang, W., Shi, X.-X. \& You, S.-L. Dearomatization of tryptophols via a vanadium-catalyzed asymmetric epoxidation and ringopening cascade. Chem. Commun. 50, 1231-1233 (2014).

32. Zi, W., Zuo, Z. \& Ma, D. Intramolecular dearomative oxidative coupling of indoles: a unified strategy for the total synthesis of indoline alkaloids. Acc. Chem. Res. 48, 702-711 (2015).

33. Gentry, E. C., Rono, L. J., Hale, M. E., Matsuura, R. \& Knowles, R. R. Enantioselective synthesis of pyrroloindolines via noncovalent stabilization of indole radical cations and applications to the synthesis of alkaloid natural products. J. Am. Chem. Soc. 140, 3394-3402 (2018).

34. Tomakinian, T., Guillot, R., Kouklovsky, C. \& Vincent, G. Direct oxidative coupling of $\mathrm{N}$-acetyl indoles and phenols for the synthesis of benzofuroindolines related to phalarine. Angew. Chem. Int. Ed. 53, 11881-11885 (2014).

35. Lerch, S., Unkel, L.-N. \& Brasholz, M. Tandem organocatalysis and photocatalysis: an anthraquinone-catalyzed indole-c3-alkylation/ photooxidation/1,2-shift sequence. Angew. Chem. Int. Ed. 53, 6558-6562 (2014).

36. Nagaraju, K. \& Ma, D. Oxidative coupling strategies for the synthesis of indole alkaloids. Chem. Soc. Rev. 47, 8018-8029 (2018).

37. Zi, W., Xie, W. \& Ma, D. Total synthesis of akuammiline alkaloid (-)-vincorine via intramolecular oxidative coupling. J. Am. Chem. Soc. 134, 9126-9129 (2012).

38. An, J., Zou, Y.-Q., Yang, Q.-Q., Wang, Q. \& Xiao, W.-J. Visible light-induced aerobic oxyamidation of indoles: a photocatalytic strategy for the preparation of tetrahydro-5h-indolo[2,3-b]quinolinols. Adv. Synth. Catal. 355, 1483-1489 (2013).

39. Al Osaimi, A. G., Ali, R. S., Saad, H. A. \& El Sayed Aly, M. R. Synthesis and antimicrobial activity of novel fused $[1,2,4]$ triazino[5,6-b]indole derivatives. Russ. J. Gen. Chem. 87, 1246-1255 (2017).

40. Takayama, H. et al. New procedure to mask the 2,3- $\pi$ bond of the indole nucleus and its application to the preparation of potent opioid receptor agonists with a corynanthe skeleton. Org. Lett. 8, 5705-5708 (2006).

41. Bonderoff, S. A. \& Padwa, A. Polycyclic ring formation using bis-diazolactams for cascade stitching. J. Org. Chem. 82, 642-651 (2017).

42. Xu, Z., Wang, Q. \& Zhu, J. Total syntheses of (-)-mersicarpine, $(-)$-scholarisine $\mathrm{g},(+)$-melodinine e, $(-)$-leuconoxine, $(-)$-leuconolam, $(-)$-leuconodine a, $(+)$-leuconodine $\mathrm{f}$, and (-)-leuconodine c: Self-induced diastereomeric anisochronism (sida) phenomenon for scholarisine g and leuconodines a and c. J. Am. Chem. Soc. 137, 6712-6724 (2015).

43. Hari Narayana Moorthy, N. S., Karthikeyan, C. \& Trivedi, P. Design, synthesis, cytotoxic evaluation, and QSAR study of some $6 \mathrm{H}$-indolo[2,3-b] quinoxaline derivatives. J. Enzym. Inhib. Med. Chem. 25, 394-405 (2010).

44. Singh, D. P., Grover, V., Kumar, R. \& Jain, K. Template synthesis of macrocyclic complexes and their spectroscopic and antibacterial studies. $J$. Enzym. Inhib. Med. Chem. 25, 445-449 (2010).

45. Okada, Y. \& Chiba, K. Redox-tag processes: Intramolecular electron transfer and its broad relationship to redox reactions in general. Chem. Rev. 118, $4592-4630$ (2018).

46. Jutand, A. Contribution of electrochemistry to organometallic catalysis. Chem. Rev. 108, 2300-2347 (2008). 
47. Fu, N., Sauer, G. S. \& Lin, S. Electrocatalytic radical dichlorination of alkenes with nucleophilic chlorine sources. J. Am. Chem. Soc. 139, 15548-15553 (2017).

48. Yang, Q.-L. et al. Palladium-catalyzed C(sp3)-H oxygenation via electrochemical oxidation. J. Am. Chem. Soc. 139, 3293-3298 (2017).

49. Yoshida, J.-i, Kataoka, K., Horcajada, R. \& Nagaki, A. Modern strategies in electroorganic synthesis. Chem. Rev. 108, 2265-2299 (2008).

50. Siu, J. C. et al. Electrochemical azidooxygenation of alkenes mediated by a Tempo-N3 charge-transfer complex. J. Am. Chem. Soc. 140, 12511-12520 (2018).

51. Fu, N., Sauer, G. S., Saha, A., Loo, A. \& Lin, S. Metal-catalyzed electrochemical diazidation of alkenes. Science 357, 575 (2017).

52. Hou, Z.-W. et al. Electrochemical $\mathrm{C}-\mathrm{H} / \mathrm{N}-\mathrm{H}$ functionalization for the synthesis of highly functionalized (aza)indoles. Angew. Chem. Int. Ed. 55, 9168-9172 (2016).

53. Francke, R. \& Little, R. D. Redox catalysis in organic electrosynthesis: basic principles and recent developments. Chem. Soc. Rev. 43, 2492-2521 (2014).

54. Siu, J. C., Parry, J. B. \& Lin, S. Aminoxyl-catalyzed electrochemical diazidation of alkenes mediated by a metastable charge-transfer complex. J. Am. Chem. Soc. 141, 2825-2831 (2019).

55. Xu, G. \& Moeller, K. D. Anodic coupling reactions and the synthesis of Cglycosides. Org. Lett. 12, 2590-2593 (2010).

56. Huang, C., Qian, X.-Y. \& Xu, H.-C. Continuous-flow electrosynthesis of benzofused S-heterocycles by dehydrogenative C-S cross-coupling. Angew. Chem. Int. Ed. 58, 6650-6653 (2019).

57. Xu, H.-C. \& Moeller, K. D. Intramolecular anodic olefin coupling reactions Use of the reaction rate to control substrate/product selectivity. Angew. Chem. Int. Ed. 49, 8004-8007 (2010).

58. Yan, H., Hou, Z.-W. \& Xu, H.-C. Photoelectrochemical C-H alkylation of heteroarenes with organotrifluoroborates. Angew. Chem. Int. Ed. 131, 4640-4643 (2019).

59. Tang, S., Liu, Y. \& Lei, A. Electrochemical oxidative cross-coupling with hydrogen evolution: a green and sustainable way for bond formation. Chem. 4 27-45 (2018).

60. Waldvogel, S. R., Lips, S., Selt, M., Riehl, B. \& Kampf, C. J. Electrochemical arylation reaction. Chem. Rev. 118, 6706-6765 (2018).

61. Sauermann, N., Meyer, T. H., Tian, C. \& Ackermann, L. Electrochemical cobalt-catalyzed C-H oxygenation at room temperature. J. Am. Chem. Soc. 139, 18452-18455 (2017)

62. Redden, A., Perkins, R. J. \& Moeller, K. D. Oxidative cyclization reactions: Controlling the course of a radical cation-derived reaction with the use of a second nucleophile. Angew. Chem. Int. Ed. 52, 12865-12868 (2013).

63. Jiang, Y., Xu, K. \& Zeng, C. Use of electrochemistry in the synthesis of heterocyclic structures. Chem. Rev. 118, 4485-4540 (2018).

64. Liu, K., Tang, S., Huang, P. \& Lei, A. External oxidant-free electrooxidative $[3+2]$ annulation between phenol and indole derivatives. Nat. Commun. 8, 775 (2017).

65. Cai, C.-Y. \& Xu, H.-C. Dehydrogenative reagent-free annulation of alkenes with diols for the synthesis of saturated o-heterocycles. Nat. Commun. 9, 3551 (2018).

66. Ma, Y. et al. Electrochemical [4+2] annulation-rearrangement-aromatization of styrenes: Synthesis of naphthalene derivatives. Angew. Chem. Int. Ed. 58, 6756-6760 (2019).

67. Zhang, G. et al. Oxidative [4+2] annulation of styrenes with alkynes under external-oxidant-free conditions. Nat. Commun. 9, 1225 (2018)
68. Wu, J., Dou, Y., Guillot, R., Kouklovsky, C. \& Vincent, G. Electrochemical dearomative 2,3-difunctionalization of indoles. J. Am. Chem. Soc. 141, 2832-2837 (2019).

\section{Acknowledgements}

This work was supported by the National Natural Science Foundation of China (21520102003) and the Hubei Province Natural Science Foundation of China (2017CFA010). The Program of Introducing Talents of Discipline to Universities of China (111 Program) is also appreciated.

\section{Author contributions}

A.L. and K.L. contributed to the conception and design of the experiments. K.L., W.S. Y.D., H.Y., C.S. and T.A. performed the electrochemical synthesis. K.L. and S.W. performed the EPR experiments. H.C. resolved the X-ray structure. K.L., S.T. and A.L. cowrote the manuscript contributed to data analysis and scientific discussion.

\section{Competing interests}

The authors declare that they have no conflicts of interest.

\section{Additional information}

Supplementary information is available for this paper at https://doi.org/10.1038/s41467 019-13829-4.

Correspondence and requests for materials should be addressed to A.L.

Peer review information Nature Communications thanks the anonymous reviewers for their contribution to the peer review of this work.

Reprints and permission information is available at http://www.nature.com/reprints

Publisher's note Springer Nature remains neutral with regard to jurisdictional claims in published maps and institutional affiliations.

Open Access This article is licensed under a Creative Commons Attribution 4.0 International License, which permits use, sharing, adaptation, distribution and reproduction in any medium or format, as long as you give appropriate credit to the original author(s) and the source, provide a link to the Creative Commons license, and indicate if changes were made. The images or other third party material in this article are included in the article's Creative Commons license, unless indicated otherwise in a credit line to the material. If material is not included in the article's Creative Commons license and your intended use is not permitted by statutory regulation or exceeds the permitted use, you will need to obtain permission directly from the copyright holder. To view a copy of this license, visit http://creativecommons.org/ licenses/by/4.0/.

(C) The Author(s) 2020 